Revista Interdisciplinaria de Humanidades, Educación, Ciencia y Tecnología

Año VII. Vol. VII. N³. Edición Especial III. 2021

Hecho el depósito de ley: pp201602FA4721

ISSN-L: 2542-3029; ISSN: 2610-802X

Universidad Nacional Experimental Francisco de Miranda (UNEFM). Santa Ana de Coro. Venezuela

Julio Adrián Molleturo-Jiménez; Julio Enrique Molleturo-Maldonado; Juan Carlos Álvarez-Pacheco María Paola Aguilar-Rodas

DOI $10.35381 / \mathrm{cm} . v 7 i 3.588$

\title{
La salud como interés asegurable en el régimen jurídico ecuatoriano
}

Health as an insurable interest in the Ecuadorian legal regime

\author{
Julio Adrián Molleturo-Jiménez \\ julio.molleturo.06@est.ucacue.edu.ec \\ Universidad Católica de Cuenca, Cuenca \\ Ecuador \\ https://orcid.org/0000-0003-2853-7793 \\ Julio Enrique Molleturo-Maldonado \\ julio.molleturom@ucacue.edu.ec \\ Universidad Católica de Cuenca, Cuenca \\ Ecuador \\ https://orcid.org/0000-0002-3759-5517 \\ Juan Carlos Álvarez-Pacheco \\ jalvarezp@ucacue.edu.ec \\ Universidad Católica de Cuenca, Cuenca \\ Ecuador \\ https://orcid.org/0000-0002-7019-9129 \\ María Paola Aguilar-Rodas \\ maria.aguilar@ucacue.edu.ec \\ Universidad Católica de Cuenca, Cuenca \\ Ecuador \\ https://orcid.org/0000-0003-2689-392X
}

Recibido: 15 de agosto de 2021

Aprobado: 15 de noviembre de 2021 


\title{
RESUMEN
}

La salud y los seguros privados en Ecuador son dos temas que, debido a nuestras construcciones sociales, no se han analizado conjuntamente, sino más bien de manera aislada. La salud, pese a ser reconocida como un derecho fundamental, es entendida por la sociedad como un servicio público, edificado sobre corrientes legislativas que lejos de ser técnicas, se han convertido en canales de ejercicios ideológicos. Los seguros, han sido concebidos bajo dos acepciones: la primera, dada la naturaleza jurídica del contrato en el que se origina, como una actividad económica; y la segunda, entendiendo su objetivo, supone admitirlo como un mecanismo de protección patrimonial. Es necesario, por lo tanto, armonizar la actualidad normativa de estas ramas, para proponer, como ya se ha hecho sana costumbre en otras legislaciones, a la salud como un objetivo de primordial interés para la industria aseguradora.

Descriptores: Política de la salud; seguro; derechos civiles. (Palabras tomadas del Tesauro UNESCO).

\begin{abstract}
Health and private insurance in Ecuador are two issues that, due to our social constructions, have not been analyzed jointly, but rather in isolation. Health, despite being recognized as a fundamental right, is understood by society as a public service, built on legislative currents that, far from being technical, have become channels for ideological exercises. Insurance has been conceived under two meanings: the first, given the legal nature of the contract in which it originates, as an economic activity; and the second, understanding its objective, supposes admitting it as a patrimonial protection mechanism. It is therefore necessary to harmonize the current regulations of these branches, in order to propose, as has already been a healthy custom in other legislations, to health as an objective of primary interest to the insurance industry.
\end{abstract}

Descriptors: Health policy; insurance; civil and political rights. (Words taken from the UNESCO Thesaurus). 


\section{INTRODUCCIÓN}

La salud y los seguros privados en Ecuador son dos temas que no han sido analizados de manera conjunta, sino más bien que se han construido de manera aislada. La salud, pese a ser reconocido como un derecho fundamental, es entendida más como un servicio público, fundado sobre corrientes legislativas. Los seguros en cambio, han sido concebidos bajo dos acepciones: la primera, dada la naturaleza jurídica del contrato en el que se origina, es concebirlo como una actividad económica, y la segunda, entendiendo su objetivo, es admitirlo como un mecanismo de protección. En ningún caso, se han conjuntado los entes rectores de cada rama para siquiera, entender el giro de cada una de estas industrias y su relación con los derechos sentados en la carta magna, de cuyos mandatos se desprende otros derechos.

En tal motivo, es necesario enlazar la actualidad normativa de estas ramas, para proponer a la salud como un objetivo de primordial interés para la industria aseguradora dado su fin social y su vínculo con el ejercicio de la salud como profesión. Será necesario entonces, conocer cuáles son los principios fundamentales del seguro que, constituidos como mandatos de optimización, tienden al desarrollo de derechos, específicamente el principio conocido como interés asegurable. De forma paralela, es elemental comprender porque la salud se construye como un derecho fundamental y porque entonces el acceso a la salud -no como necesidad terapéutica- sino como un derecho natural debe considerarse de manera autónoma como un interés asegurable propio.

Una vez que hayamos comprendido esta autónoma rama, es oportuno encontrar el medio para la consecución de tal fin, y entonces a la luz del derecho de reparación, la comprensión de la esencia de los seguros de daños y responsabilidad civil, y sus diferencias, estableceremos la necesidad de que la concreción de estos riesgos y sus consecuencias estén aseguradas de manera que su cobertura resulte un imperativo en los actos de salud. 


\section{Referencial teórico}

\section{Principios generales del contrato de seguros y su vigencia dentro del sistema jurídico ecuatoriano.}

\section{Generalidades de los seguros}

El mundo cambió a raíz de la pandemia en la gran mayoría de los aspectos, tanto en aquellos que suponen grandes modificaciones estructurales, cuanto aquellos que son más bien nuevos pasos en las rutinas del día a día, así ese ímpetu de hombres y mujeres de precautelar las cosas propias se ha convertido más que nunca en la necesidad de encontrar inefablemente lo que se ha obtenido.

Un breve análisis que clarifique a la industria aseguradora, debe considerar la evolución socio-económica de la sociedad, más todavía cuando lo que busca comprender es el vínculo que puede tener esta industria, con un derecho fundamental como la salud o con el ejercicio de una profesión, así desde estas dos aristas la esencia del seguro será la reparación o la indemnización de las pérdidas o daños a los que están expuestos el patrimonio, la economía, la integridad física y la vida de las personas, indemnización o reparación sin la cual el objeto mismo del contrato pierde sentido.

Hoy, el contrato de seguros en Ecuador, pese a la transición del Decreto Supremo 1147 al nuevo Código de Comercio, promulgado en el año 2019, aún es deficiente desde la normativa de seguros, la misma que se limita a describir de manera general el contenido de la póliza o contrato, los tipos de seguros y a establecer derechos y obligaciones sobre la ejecución propia del contrato, sin embargo, no existe una vinculación directa entre la normativa aseguradora y otros aspectos fundamentales para esa relación socio económica como por ejemplo la salud. 


\section{Evolución histórica en Ecuador}

La comercialización de una suerte de seguros marítimos por intermedio de unas pocas compañías extranjeras a finales del siglo decimonónico, es quizás la referencia inicial de la actividad aseguradora en Ecuador; ese creciente mercado ejecutado por extranjeros causó que el gobierno de turno sienta la necesidad de regular estas actividades inicialmente por la capacidad de estas personas jurídicas para operar en el país.

De esta manera, al analizar bases de datos jurídicos, nos remitiremos al primer Código de Comercio cuya promulgación vigencia y autenticidad se decreta en agosto de 1906; siendo de manera posterior en el año 1909 la primera referencia de una LEY DE COMPAÑIAS.

Los flagelos de Guayaquil, cuyos contratos de seguros estaban suscritos con compañías extranjeras, motivaron que el Decreto Legislativo (DL) contenido en el Registro Oficial (R.O) noviembre del año 1917 le otorgue a las compañías de seguros extranjeras la posibilidad de suscribir contratos para la cobertura de estos riesgos en el Ecuador (Ecuador, 1920)

Luego de esto, existe una época de importante crecimiento asegurador entre el 1920 y 1955, la misma que se caracteriza principalmente por la ayuda que la misión Kemmerer, prestó al estado para la conformación de la Superintendencia de Bancos en septiembre de 1927. En el último mes del año 1933 se promulga el primer acto legislativo para la Ley sobre Compañías de Seguros, cuyo Reglamento consta en el R.O. 0071 de enero de 1934, año en el que también se publica su primera reforma, la cual se mantiene vigente a la actualidad y versa sobre el plazo para la celebración de la escritura pública de declaración del capital.

En 1935 se publica la Ley General de Seguros que norma el plazo para que las aseguradoras extranjeras obtengan la venia correspondiente para pactar operaciones en territorio ecuatoriano, teniendo como mandato el invertir en bienes inmuebles o cédulas 
hipotecarias, siendo obligatorio que las ejecuciones de los contratos de seguros sigan la legislación ecuatoriana (Ley General de Seguros, 2016).

A partir de 1955, inicia la "época actual" representada por dos hechos importantes, el primero la organización de la actividad aseguradora mediante sociedades ecuatorianas bajo la tutela de las compañías extranjeras que "patrocinaron" su creación, y el segundo, por la creación, regulación y comercialización de nuevas coberturas de seguros, entre estos el de responsabilidad civil (Rodríguez, 2014).

En diciembre de 1963, se promulga el R.O. 123 que contenía el Decreto Supremo 1147 y cuyo contenido incluía las nuevas normas relativas al Contrato de Seguro y la estructura de la póliza, norma que estuvo vigente hasta que el 14 de mayo del 2019 la Asamblea Nacional expide el Nuevo Código de Comercio, publicado en el Registro Oficial Suplemento (R.O.S.) 497 del 29 de mayo del 2019, en específico el libro sexto el contrato de seguros en una copia casi integra del decreto 1147.

\section{Constitución del Ecuador 2008}

El estado constitucional de derechos y justicia, vigente desde octubre del 2008, no tiene un pronunciamiento expreso respecto al sistema de seguros privados, salvo en cuanto a la obligación que le genera para su aportación económica a favor del seguro social. Este, es quizás el primero de los problemas que se tienen al momento de tratar de vincular a la industria aseguradora con el ejercicio de derechos fundamentales, causando que se invisibilise la función reparadora y social del contrato de seguros.

\section{Código Orgánico Monetario y Financiero (C.O.M.F), libro III: Ley General de Seguros}

Esta norma se promulga mediante el R.O. 332 de septiembre del 2014 y contiene dentro de su libro III a la Ley General de Seguros (2016) que regula principalmente tres aspectos: 1. La conformación, organización y funcionamiento de quienes integran el régimen de 
seguros privado, es decir, aseguradoras y reaseguradoras, intermediarios y peritos de seguros. 2. El reclamo administrativo en materia de seguros, y 3 . Los contratos de seguros de fianzas. Esta norma no hace mayor referencia al contrato de seguros, por lo que, desde la operatividad del contrato, no existe, salvo ciertos ramos, una disposición de carácter orgánico.

\section{Código de Comercio}

El Código de Comercio de mayo de 2019, en un ejercicio similar a lo hecho por el legislativo en la promulgación del C.O.M.F, contrario a desarrollar el sistema de seguros y su normativa, contiene únicamente un ejercicio de trasladar lo expuesto en el Decreto Supremo 1147 al libro Sexto de dicho cuerpo, es decir, no existen cambios importantes -como ya se dijo, casi 5 décadas después- hecho que cierra la puerta a un cambio de fondo en la estructura del contrato y en el día a día de la actividad aseguradora. En lo principal, esta norma expone de manera simple los tipos de seguros, habiéndose también desperdiciado una oportunidad para sentar las bases de un desarrollo técnico-legislativo para los seguros.

\section{Ley que regula a las compañías de salud prepagada y de asistencia médica}

Es quizás el único cuerpo de carácter orgánico, que regula un tipo de seguro, tanto así que el mismo artículo 779 del Código de Comercio, previo a introducirse en el desarrollo del ramo, anticipa que sin afectar lo establecido en otras normas, debido a que la ley entra en vigencia mediante el R.O. 863 de octubre de 2016, es decir y propio de un ejercicio no técnico del legislativo de turno, reguló orgánicamente un ramo de seguros que se encuentra contenido en una norma jerárquicamente inferior. Esta ley, regula la creación y actividad de personas jurídicas que desarrollen servicios de salud integral y es la primera norma en materia de seguros que vincula a principios constitucionales con reglas y normas para su ejecución, así se incorpora como eje para la prestación de estos 
servicios y como tal para este tipo de seguros principios de equidad, igualdad, no discriminación, bioética entre otros, siendo la referencia principal de la salud como un derecho fundamental para los seguros, sumado a esto que el libro tercero del C.O.M.F, incorpora al régimen de seguros a todo aquello que sea aplicable y que conste en la Ley Orgánica de Defensa del Consumidor.

\section{Codificación de resoluciones de la Superintendencia de Compañías, Valores y Seguros}

Dichas resoluciones tienen un carácter general de aplicación y pretende llevar a la práctica parámetros establecidos en las normas orgánicas y ordinarias descritas brevemente. Entre las más importantes podríamos ubicar a las que establecen el mecanismo para la presentación de reclamos y aquella que establece que cláusulas están permitidas y/o prohibidas en los contratos de seguros.

\section{Características de los contratos de seguros}

La actualidad de los contratos de seguros que se emiten y suscriben tienen características generales y específicas, las cuales tienden a demarcar el accionar de estos. Como no es extraño en la legislación ecuatoriana, este contrato no tiene una definición positiva en cuanto a sus características por lo que las mismas deben establecerse de manera general desde la doctrina, así, el autor más claro para este ejercicio es Peña (1999) quien al momento de caracterizar al contrato de seguros detalla cinco particularidades: bilateral, oneroso, principal, conmutativo y aleatorio.

Bilateral en cuanto existe una obligación recíproca entre el asegurador y el contratante -este puede ser también asegurado y/o beneficiario-, un vínculo de distintos deberes, pero de una misma obligación. Oneroso en virtud de que se debe cumplir con el pago de una prima con el acuerdo expreso del pago de la ocurrencia, las partes entonces, se gravan entre sí, en cuanto es provechoso para la empresa cobrar una prima y para el 
contratante tutelar o reparar su patrimonio. Principal, en el más claro ejemplo de la característica aportada por la norma constante en el artículo 1458 del código Civil, es decir, el contrato de seguros por regla general, no depende de otro contrato para perfeccionarse; la excepción a esta regla son los seguros de fianzas, en donde la póliza si depende de un contrato principal. Conmutativo, las prestaciones entre los contratantes son equivalentes y están compensada, ya sea por la tutela de patrimonio cuya contraprestación es la entrega de un valor llamado prima, o por el cobro de la prima que, al ser establecida técnicamente, genera utilidad respecto del desembolso de indemnizaciones. Aleatorio, característica que nace de la imprevisibilidad de la ocurrencia o no del riesgo asegurado, así una persona puede contratar un seguro y no tener nunca un siniestro y por lo tanto no hay daño indemnizable, o, puede una persona tener varios hechos indemnizables que supongan cierta pérdida para la compañía.

\section{Principios generales del seguro}

Definir a los principios, es quizás uno de los retos más importantes a través de la historia, así como dice Fazio (2019). Gracias a María Alejandra Gutiérrez Vargas (2019) podemos distinguir principalmente tres teorías, la primera, busca convencernos de que los principios son una clase de normas que dependen de su justificación moral; la segunda plantea que los principios son una clase de normas con propiedades estructurales; y, la tercera que indica que los principios desde la interpretación constitucional son normas que prescriben derechos fundamentales (Gutiérrez, 2019). Para este trabajo, analizaremos brevemente a los principios de los seguros desde la óptica de la segunda teoría, ya que, por las características del contrato de seguros y por la nula referencia constitucional a los seguros no cabría utilizar los parámetros de la primera y tercera tesis expuesta.

Así, los principios del contrato de seguros son: máxima de buena fe, interés asegurable, indemnización, subrogación, contribución y causa inmediata; nos apoyaremos para esta 
exposición en el autor chileno Osvaldo Contreras Strauch y su obra Derecho de Seguros (Contreras, 2005)

\section{Máxima de buena fe}

En materia contractual, el principio de buena fe está vinculado a todo contrato y se entiende como la obligación de ejecutar el mismo de acuerdo a las exigencias propias del objeto del contrato, así como de las normas legales o éticas que le sean atribuibles por su naturaleza, sin embargo, en materia de seguros este principio adquiere una relevancia especial que deviene de un principio propio del derecho romano, "uberrimae bonae fidei" el cual es "un estándar de conducta ética que debe presidir el ejercicio de los derechos subjetivos y los procedimientos y prácticas administrativas y procesales" (Fundación MAPFRE, 2020, párr. 1). Principio que consta en el tercer artículo del Código de Comercio.

\section{Indemnización}

El principio indemnizatorio es parte de la característica conmutativa del contrato de seguros y consiste en la restitución del patrimonio afectado, su fundamento principal está en la intención que tiene el asegurado, contratante o beneficiario, de que su patrimonio no se vea afectado, no obstante, esto se debería entender más bien, como la intención del asegurado de que su patrimonio pueda ser reparado, tanto así, que el mismo Código de Comercio (2019) en el artículo 737 establece que el resarcimiento se pagará con la obligación de dar dinero o cosas, o la obligación de reconstruir la misma. Regulada la reparación en términos del contrato de seguros, el principio de indemnización es el límite que será pagado en caso de siniestro. 


\section{Subrogación}

Cuando la compañía aseguradora, en los términos pactados en la póliza ha pagado la indemnización de un siniestro se genera un derecho a perseguir la restitución de lo pagado frente a quien haya tenido la responsabilidad del daño, para esto el asegurado debe ejecutar todo lo requerido para la compañía para la eficacia de la acción subrogatoria, la misma que podría decirse tiene un solo requisito, la indemnización del siniestro conforme a ley y contrato. Este derecho de la compañía y obligación del asegurado, es un mandato legal de obligatoria satisfacción tal como consta en el artículo 740 de Código de Comercio (2019).

\section{Contribución}

Este principio es la optimización de la figura del coaseguro, mediante el cual un mismo interés asegurable, el mismo objeto y el mismo riesgo pueden estar tutelados por dos o más aseguradores, en cuyo caso la ocurrencia del siniestro debe ser soportado e indemnizado por ambos en los porcentajes de riesgo asumidos sin que la suma de estas indemnizaciones genere un incremento en el patrimonio del asegurado.

\section{Causa inmediata}

La indemnización del siniestro puede estar sujeta al análisis de la causa que generó el daño. Así, para que se genere la obligación de reparar debe existir un hecho amparado por la póliza cuya eficiencia haya producido el resultado. Por lo tanto, cuando la disposición 695 del Código de Comercio define como siniestro a la materialización del riesgo, se refiere a la causa dominante que permitió la configuración de ese hecho dañoso. Para comprender mejor esto plantearemos un ejemplo sencillo: a la hora de indemnizar un siniestro de una póliza de vida, la compañía no debe analizar las distintas razones que llevaron al fallecimiento del asegurado, sino que surge la obligación de indemnizar con la muerte de éste por el simple hecho de haber ocurrido. Lo que permite 
este principio es que la causa útil deba ocurrir siempre y cuando la misma este amparada bajo los términos pactados en la póliza.

\section{Interés asegurable}

Este es el principio sobre el cual gira este trabajo. El artículo 694 del código de comercio establece que todo aquello en lo que el asegurado pueda hacer una estimación monetaria y que sea lícito, es un interés asegurable. En términos económicos el vínculo es claro, pero además en términos jurídicos ese nexo debe constituirse como un puente legítimo y legal entre el patrimonio y el sujeto. La legitimidad y legalidad que deben existir, al tenor de una constitución de derechos y justicia no nace entonces solo desde el aspecto económico sino además desde la necesidad de tutelar derechos fundamentales que puedan ser estimados en dinero, cuyo caso más evidente es la salud. El interés asegurable dependiendo del tipo de seguro tendrá un origen distinto, para los seguros de daños, el derecho a la propiedad; para los seguros de personas, la integridad física y/o salud, y para las pólizas de responsabilidad civil, la potencial atribución de responsabilidad.

\section{La salud como un derecho fundamental y su vinculación desde el contrato de seguros.}

\section{La salud como un derecho fundamental para el ejercicio de otros derechos.}

A partir del 2008, el Ecuador, consolidado como un Estado de derechos y justicia, hecho que faculta la integración normativa entre sistemas jurídicos nacionales e internacionales, de esta manera mantenemos un sistema de justicia multinivel.

El primer nivel, el régimen jurídico interno, conformado por las normas constitucionales, la legislación orgánica, ordinaria y la normativa dictada por el Ministerio de Salud Pública; el segundo nivel, tiene relación con el sistema de la Convención Americana de Derechos Humanos. Estos niveles entonces, configuran un conjunto de normas que tienen como 
objetivo tutelar el ejercicio de derechos fundamentales en lo que se conoce como bloque de constitucionalidad.

El artículo 32 de la Constitución, consolida a la salud como un derecho fundamental, mediante el cual se permite o faculta la realización y ejercicio de otros derechos. Previo a analizar la obligación que tiene el Estado en relación a la salud, es necesario considerar que dentro de los deberes primordiales del Estado se encuentra la garantía de que derechos como la salud, que además está protegido internacionalmente, sea cumplido en debida forma por el Estado.

Para este fin, como ya mencionamos, el Estado Ecuatoriano debe ejecutar normas internacionales y nacionales y en su ejercicio debe adecuar su estructura de tal manera que el acceso a la salud satisfaga el derecho constitucionalmente consagrado, debiendo garantizar la fomento y atención integral en salud.

Por lo tanto, la salud como en derecho fundamental formal y material -formal por estar positivizado como tal y material por su inherencia con el ser humano- esta tutelada desde el sistema jurídico interno principalmente con los artículos 3, 11, 32 y 358 de la Constitución, y, por el sistema jurídico internacional con el protocolo de San Salvador artículo 10, por el artículo 5 de la CADH y por multiplicidad de sentencias de la CIDH; como una categoría reforzada de protección es entonces un derecho fundamental y objeto de protección directa.

\section{Legislación de la salud en el sistema jurídico ecuatoriano}

Desde la óptima del sistema jurídico interno, la salud como un derecho fundamental se consagra, como ya mencionamos, en el artículo 32 de la Constitución; a partir de esto, el Estado tiene el deber de crear y regular todo el sistema de salud conformado por el ordenamiento jurídico, la infraestructura y los recursos que facultan la promoción y atención de salud. 
El Sistema Nacional de Salud -artículo 358 Constitución- tiene como objetivo la protección de las capacidades de las personas para un desarrollo individual o colectivo de una vida saludable y comprende a instituciones públicas y privadas, así lo establece el artículo 362.

Entonces, debemos volver sobre la jerarquía normativa del 425 de la Constitución para identificar la legislación de salud, partiendo de las normas orgánicas tenemos a la ley orgánica de salud y la ley orgánica del sistema nacional de salud, la primera que tiene como finalidad regular el acceso a la salud, definir las competencias del Ministerio de Salud Pública y los derechos del Estado en relación a la salud. La segunda, busca definir los estándares de organización y funcionamiento del sistema nacional, el establecimiento del plan integral y la conformación y manejo del sistema.

Estas normas, pese a ser originalmente expedidas de forma previa a la Constitución del 2008, tienen adecuaciones que obligan a que el Estado en relación a la salud, desde su acceso hasta su funcionamiento garantice el acceso a la salud bajo el parámetro de principios establecidos y que devienen de la legislación ecuatoriana e internacional como se había mencionado.

En la esfera ordinaria del ordenamiento normativo en salud, el Ecuador hace gala de su escaza técnica legislativa a lo largo de su historia, pues existe una inmensa cantidad de leyes que se relacionan con la salud, sin embargo, la que más llama la atención -para este trabajo- es la Ley de derechos y amparo al paciente que consta en el R.O.S 626 del 3 de febrero de 1995 y cuya actual reforma integral data del 22 de diciembre del 2006. En esta se define con certeza los derechos del paciente a una atención digna, no discriminación, confidencialidad, información y decisión, definiciones importantes y que han sido la base para la emisión de otros cuerpos normativos que regulan el ejercicio de estos derechos como, especialmente el Acuerdo Ministerial 5316 Modelo de aplicación del consentimiento informado y el Acuerdo Ministerial 5216 Reglamento de información 
confidencial en sistema nacional de salud, no obstante, también en este nivel normativo existe gran cantidad de acuerdos o resoluciones de la autoridad en materia de salud.

\section{La salud desde la legislación de seguros del Ecuador}

En materia de seguros, la situación es diferente en relación de la normativa de salud, la Constitución de la República no reconoce a los seguros, sino a través de la obligación que le impone para su aportación al Seguro Social Campesino; son otras normas de carácter infra constitucional las que regulan el contrato de seguros, como ya se advirtió, posiblemente, la única norma que contenga un vínculo normativo entre el derecho a la salud y los seguros es la Ley regula a las Compañías de salud prepagada y asistencia médica y su reglamento general, situación que tanto impide la profundización de esta importante área, cuanto dificulta el crecimiento de la cultura aseguradora en el imaginativo social de los ciudadanos.

Diversos países y legislaciones en el mundo han comprendido la relación cercana existente entre la salud y los seguros, a tal punto que la misma OMS se ha pronunciado sobre la importancia de vincular normativamente a los regímenes de salud públicos con los sistemas de seguros privados dadas sus características, tanto así que países como Argentina, Uruguay y Chile son parte de un conglomerado de países con alto índice de participación del gasto en seguros privados en referencia al gasto total en salud.

Este ejercicio entonces es importante en el Ecuador debido a que, por la falta de capacidad estatal para garantizar herramientas útiles garantizar el acceso a la salud, se hace fundamental la incorporación de los seguros como un instrumento más para la satisfacción o acción de este derecho. Para tal efecto es indispensable que previo a este vínculo, se pueda concretar a los seguros no solo como una actividad mercantil, sino como una actividad que en palabras de Issac Halperin y Félix Morandi (1991): "El seguro crea seguridad, capitales y crédito. Crea seguridad en cuanto crea la protección en la medida que satisface la necesidad eventual suscitada por el riesgo. En esta medida 
repercute en la economía, al desarrollar el espíritu de empresa, mejorar los medios de producción (...)" (pg. 29), pueda ser entendida con un objetivo de protección económica de los individuos y la sociedad.

\section{Los seguros de responsabilidad civil profesional como una obligación para el ejercicio de los actos médicos.}

\section{Los seguros de responsabilidad civil}

El artículo 752 del Código de Comercio establece: "En los seguros de responsabilidad civil, el asegurador debe satisfacer, dentro de los límites fijados en el contrato, las indemnizaciones pecuniarias que, de acuerdo con las leyes, esté obligado a pagar el asegurado, como civilmente responsable de los daños causados a terceros, por hechos previstos en el contrato. Son asegurables la responsabilidad contractual y la extracontractual, al igual que la culpa grave" articulado del cual se deducen dos premisas, la primera, un vínculo de carácter civil, exista o no una relación contractual de por medio, y la segunda, la responsabilidad generada frente a un tercero.

A pesar de esto, el legislador, no ha podido reflejar el ejercicio de este tipo de seguros y por ende, lo que existe en la legislación específica y general resulta insuficiente para un ejercicio contractual que crece constantemente y que trata de adecuarse al dinámico desarrollo de las relaciones jurídicas.

El seguro de responsabilidad civil por lo tanto debería abordarse desde dos instituciones que, siendo independientes, se acoplan para garantizar el vínculo económico -interés asegurable- que tiene una persona no solo en no causar daño a un tercero, sino que, ese daño, una vez causado, sea reparado sin una afectación patrimonial (Moreno, 2018). Con lo expuesto, el seguro de responsabilidad puede obedecer a distintas acciones, ocupaciones o profesiones, sin que esto signifique una modificación de la esencia propia de este seguro. 


\section{Generalidades}

El seguro tiene como objeto indemnizar la ocurrencia de un riesgo que, una vez que se ha concretado, genera un perjuicio económico; en las pólizas de responsabilidad civil, ese riesgo convertido en daño no impacta en el patrimonio directo del asegurado por sí solo, sino en medida de que ese riesgo se haya materializado en el patrimonio de un tercero en cuyo caso surge una obligación de dar.

Por lo tanto, el interés asegurable, en los seguros de responsabilidad civil se encuentra en la necesidad de que el patrimonio de un asegurado no se perjudique por un hecho cuya responsabilidad le compete y que ha sido declarada.

\section{Características.}

Desde la doctrina pueden establecerse diversas características para los seguros de responsabilidad civil, pasando por la obligación de responder, por los fundamentos filosóficos o los fundamentos económicos de este ramo, pero estos no han sido necesariamente recogidos por la normativa, por lo que resultaría poco aplicable un análisis profundo de los mismos; por lo tanto, podríamos decir que la principal característica de estos en el Ecuador, deviene de la máxima jurídica Alterum non laedere -el deber de no dañar a nadie-, esto por cuanto solo es el daño a otro lo que infiere realmente en el seguro de responsabilidad civil.

En el capítulo segundo del libro sexto del Código de Comercio, artículos 752 al 758, sin ser taxativas, la norma nos entrega ciertas características para el seguro de responsabilidad civil, las mismas que pueden agruparse en dos grupos, el primero relacionado a las características generales, es decir, aplicables a todo seguro de responsabilidad civil y que son: A. Su cobertura está limitada únicamente a acciones culposas, B. El límite a indemnizar es el máximo establecido en la póliza, y C. la prohibición de acuerdo o transacción por parte del asegurado; luego están las características especiales, las mismas que se aplicarán o no dependiendo del tipo de 
responsabilidad civil contratada: A. obligatoriedad del asegurado para garantizar el patrocinio por parte de la aseguradora y B. la capacidad profesional del asegurado para el ejercicio de su profesión.

En la práctica, quizás la característica más importante del seguro de responsabilidad civil está relacionada al tipo de daño sobre el cual se genera la obligación de reparar; ese hecho dañoso, esa plasmación del riesgo debe -en materia de responsabilidad civilnecesariamente afectar a un tercero, de no ser así, ese hecho puede afectar el patrimonio propio por su sola ocurrencia, en ese caso estaríamos frente a un interés asegurable propio del seguro de daños.

\section{El siniestro en el contrato de seguros de responsabilidad civil profesional}

El artículo 722 del Código de Comercio indica que el siniestro es la ocurrencia del riesgo asegurado, situación con cual coincidimos. Ahora, en materia de responsabilidad civil ese siniestro, no debe ser confundido, aunque los hechos así lo permitan, con las causas por las cuales se generó el mismo, en otros términos, el siniestro debe analizarse desde la perspectiva del asegurado y no del tercero perjudicado, pues lo cierto es, que los contratos de seguros de responsabilidad civil, no son seguros a favor de un tercero, esto con fundamento en el artículo 757 de la norma que regula el contrato de seguros.

Por esto, diremos, que el siniestro en materia de responsabilidad civil nace cuando el tercero perjudicado hizo valer su derecho de reparación en la vía correspondiente, sin que sea en la mayoría de los casos obligatorio la sentencia correspondiente. Guardando relación con lo que hemos expuesto en los dos primeros capítulos, es necesario recordar que, en el Ecuador, entre los seguros y el derecho a la salud, no existe una vinculación plena, salvo contadas excepciones, una de estas se puede entender con la siguiente consulta: ¿Qué pasa cuando, en el ejercicio de la salud como un derecho, un profesional de la salud genera una lesión o muerte a un paciente?, y aquí nos encontramos con otro conflicto teórico que tiene una solución en un análisis realizado desde las coberturas de 
este seguro, puntualmente cuando hablamos de las coberturas del seguro de responsabilidad civil profesional.

Como ya mencionamos, el 752 del código de comercio establece las coberturas del seguro de responsabilidad civil -indemnización pecuniaria a un tercero- en casos de responsabilidad civil, a pesar de esto, se genera la duda cuando, al tenor de lo establecido en los artículos 146 y 152 del Código Orgánico Integral Penal en los casos de homicidio culposo por mala práctica profesional y las lesiones causadas por infringir el deber objetivo de cuidado.

Por una parte, tenemos que el seguro de responsabilidad civil profesional, tiene como objeto cubrir las indemnizaciones que devienen de un proceso de responsabilidad civil, por otra, ¿qué pasa con aquellas que devienen de una responsabilidad penal?, pues bien, en nuestro criterio el artículo 753 del Código de Comercio nos da la respuesta, más allá de que los gastos por patrocinio también pueden ser asumidos en el proceso civil, el seguro de responsabilidad civil, cuando el siniestro se produce desde la óptica de la responsabilidad penal y de manera específica en el caso de los delitos de los artículos 146 y 152 del Código Orgánico Integral Penal, esta cobertura por responsabilidad se extiende y por lo tanto se procede al pago del valor dispuesto como indemnización y al pago de los valores que por concepto de honorarios se hayan generado, esto con el único requisito que la causa que genera el daño o las causas, no provengan del dolo del asegurado.

\section{La salud como interés asegurable}

Una vez que hemos realizado un recorrido sobre la vigencia del contrato de seguros y sus principios, destacando el interés asegurable, partiendo sobre una breve descripción sobre la salud como derecho constitucional y como un puente de realización de otros derechos, es momento de encontrar a la salud como un interés asegurable propio. 
El accionar de los profesionales de la salud, sin importar que ese actor médico nazca de un vínculo contractual o no, o de una obligación de medios o resultados, se encuentra en un permanente estado de precaución por los riesgos propios de la práctica profesional en salud; médicos, enfermeros, odontólogos, psicólogos, auxiliares y profesionales de la salud en general tienen una indisoluble relación con actos que potencialmente pueden producir daños que, reclamados o no adecuadamente, faculten una responsabilidad, es decir, el accionar de los actos mediante los cuales se garantiza la prestación de salud, tiene un constante riesgo de que el daño materializado provoque una responsabilidad indemnizable y por lo tanto un siniestro, entonces la garantía de acceso a la salud, a la atención integral en materia de salud, la prestación de servicios de salud puede constituirse como un interés asegurable propio.

Es claro que, sobre la salud, desde el concepto de la Organización Mundial de la Salud (2021): "La salud es un estado de completo bienestar físico, mental y social, y no solamente la ausencia de afecciones o enfermedades" (párr. 1), toda persona tiene un interés asegurable que radica en que la ausencia de ésta, puede generar un perjuicio económico que quizás puede no recomponerse, pero es más claro aún que, acerca de la prestación de los servicios de salud, las personas tienen un vínculo económico legal y legítimo que nace desde la consagración de la vida y la integridad personal a una persona o grupo de personas las cuales, debidamente acreditadas tienen la obligación de mantener íntegra -aquí la integridad no obedece a un factor propio del prestador, si no a la ausencia de errores- la vida y/o bienestar de las personas. Entonces, existe interés asegurable en la salud desde la óptica del paciente.

Así mismo, desde la óptica del profesional de la salud, existe un interés asegurable en la salud del paciente, cuyo nexo es el interés económico de que, los riesgos propios de la intervención no se materialicen y que, materializados, no afecten por un ejercicio de atribución de responsabilidad, el patrimonio de quien presta esos actos de salud. 
Este hecho practico, no está consagrado en la normativa ecuatoriana desde la visión social ni económica del seguro, por el contrario, nada dice la legislación al respecto; este problema únicamente puede solucionarse sobre la base de algo que, en países vecinos como Colombia y Chile tiene años de ejecución, y que, en el nuestro, puede ser un soporte básico, pero también una obligación que la Autoridad Competente señale.

En otros ejercicios profesionales, como la misma asesoría y producción de seguros de vida y/o asistencia médica, quienes tengan la calificación de asesores productores de seguros, tienen la obligación de contratar un seguro de responsabilidad civil que permita cubrir posibles daños a terceros, cuesta pensar entonces, porque en un ámbito de mayor trascendencia y que cuenta incluso con un reconocimiento de justicia multinivel como la salud, no se exige que para el ejercicio de estos actos, se deba contar con un seguro de responsabilidad civil, el mismo que permita por una parte reparar un patrimonio perjudicado 'paciente, sin importar el tipo de patrimonio y por otra, tutelar también un patrimonio el del 'profesional de la salud'.

La no obligatoriedad de este seguro de responsabilidad civil pudiera quizás entenderse como la ausencia de los medios económicos para la contratación de estas pólizas, pero este hecho también puede ser descartable, un proceso de economía de escala facilitaría la producción y suscripción de estas pólizas.

El único requisito que debe considerarse desde la redacción de la legislación de seguros para que la salud sea un interés asegurable autónomo, es que, sobre la misma, exista un nexo entre el sujeto y su ejercicio, el mismo que claramente está señalado en la norma máxima constitucional y en instrumentos internacionales, razón por la que lo que resta es la voluntad y quizás más importante aún, el conocimiento por parte de la Autoridad para la concreción de un mecanismo que puede soportar las nuevas corrientes ideológicas que criminalizan la prestación de salud sin lograr que esta criminalización repare los daños causados. 


\section{MÉTODO}

El método empleado para realizar el presente trabajo, es bibliográfico, descriptivo y analítico, teniendo como base a los aportes doctrinarios, jurisprudenciales y en la legislación vigente ecuatoriana, así como los aportes más importantes y pertinentes que reposan en libros, artículos, revistas, entre otros (Erazo, 2021).

\section{CONCLUSIONES}

La contradicción normativa que existe entre el derecho a la salud y al bienestar económico, vía un mecanismo de protección patrimonial como el seguro, no existe, en medida de que no existe ni siquiera el análisis normativo que vincule a este derecho con este mecanismo

Esa ausencia obedece a la obsolescencia de la legislación de seguros en Ecuador y a la poca técnica con la cual se ha legislado al respecto creando un ambiente de inseguridad jurídica y un inadecuado ejercicio de deberes correlativos entre los integrantes del contrato de seguros y de quienes por mandato constitucional tienen un interés económico en su salud $y / 0$ en su ejercicio profesional.

La redacción de la parte pertinente del Código de Comercio, no hace relación al universo del seguro de responsabilidad civil, sino se centra sobre todo en la responsabilidad civil profesional, hecho que genere un conflicto practico cuya resolución está a expensas del criterio de la autoridad de turno.

La medicalización de la medicina, concepto sabio otorgado por el Maestro Marcelo López Mesa, nos lleva a pensar que el legislador a satisfecho caprichos ideológicos en la construcción de normas sancionadoras sin considerar que dichas sanciones no reparan a la luz de los actos de salud, sino por el contrario ahuyentan una prestación de servicios sin reservas ni cuidados excesivos por regla general.

Esa ideología hoy positivada en la norma penal, que ya sabemos cómo es cubierta por el seguro de responsabilidad civil profesional, permite decir concluyentemente que la 
única alternativa válida frente a la escasa producción normativa, es la tutela de derechos propios por intermedio de una herramienta fundamental para los actos de salud, el seguro de responsabilidad civil, el mismo que debe ser, dado el análisis que hemos realizado, de obligatoria contratación, para quienes ejercen actos de salud, quizás cuando esto así ocurra, la discusión y sustanciación de procesos judiciales por actos de salud, ya no se desarrollarán a la luz del derecho sancionador, sino del derecho reparador.

\section{REFERENCIAS CONSULTADAS}

Contreras, O. (2005). Informe en derecho sobre el interés asegurable. Su relevancia en el seguro. Recuperado de https://www.redalyc.org/pdf/3708/370838862005.pdf

De Fazio, F. (2019). Teoría Principalista de los derechos sociales. Madrid: Marcial Pons.

Erazo Álvarez, J. C. (2021). Capital intelectual y gestión de innovación: Pequeñas y medianas empresas de cuero y calzado en Tungurahua-Ecuador. Revista De Ciencias Sociales, 27, 230-245. Recuperado a partir de https://produccioncientificaluz.org/index.php/rcs/article/view/37004

Fundación MAPFRE. (2020). Uberrimae bonae fidei (uberrimae bonae fidei). Diccionario de seguros. Recuperado de: https://n9.cl/fw9li

Gutiérrez, M. (2019). Reseña de Frederico de Fazio Teoría Principalista de los derechos sociales. Buenos Aires: Universidad de Buenos Aires. Recuperado de: https://n9.cl/gwuij

Halperin, I., \& Féliz, J. (1991). Seguros Buenos Aires. Buenos Aires: Ediciones Depalma.

Moreno, W. (2018). Reparación integral de los daños provocados por la actividad regular de la administración pública (Tesis de maestria). Recuperado de https://n9.cl/s74nj

Organización Mundial de la Salud. (2021). ¿Cómo define la OMS la salud? Recuperado 8 de noviembre de 2021, de Preguntas frecuentes website: https://www.who.int/es/about/frequently-asked-questions

Peña, E. (1999). Manual de derecho de seguros (2. ${ }^{a}$ ed.). Guayaquil: Edino. 
Revista Interdisciplinaria de Humanidades, Educación, Ciencia y Tecnología

Año VII. Vol. VII. N³. Edición Especial III. 2021

Hecho el depósito de ley: pp201602FA4721

ISSN-L: 2542-3029; ISSN: 2610-802X

Universidad Nacional Experimental Francisco de Miranda (UNEFM). Santa Ana de Coro. Venezuela

Julio Adrián Molleturo-Jiménez; Julio Enrique Molleturo-Maldonado; Juan Carlos Álvarez-Pacheco

María Paola Aguilar-Rodas

Rodríguez, P. (2014). La regulación de los seguros privados de contratación masiva en la legislación ecuatoriana. 128.

(C2021 por los autores. Este artículo es de acceso abierto y distribuido según los términos y condiciones de la licencia Creative Commons Atribución-NoComercial-Compartirlgual 4.0 Internacional (CC BY-NC-SA 4.0)

(https://creativecommons.org/licenses/by-nc-sa/4.0/). 